\title{
Canadian History Podcasts
}

\section{PODCASTING HAS TAKEN OFF AMONG CANADIAN ACADEMICS,} particularly during the remote learning required by the COVID-19 pandemic, both as a tool of research dissemination and of classroom instruction. I am fortunate to collaborate with two experts in digital history: Kent Davies and Kimberley Moore of the University of Winnipeg's Oral History Centre. ${ }^{1}$ Some years ago, when I was preparing a SSHRC Insight Grant application on our behalf, Kent suggested a podcast as one of our research outcomes. "I don't know what that is," I replied, "but I'll write it down." "It's like Netflix for radio," Davies explained, before he and Moore launched a lengthy campaign to educate me. Since then, I have become a fan of $99 \%$ Invisible and the Fridge Light, while my undergraduate students, with Oral History Centre assistance, have helped generate episodes of our SSHRC-funded Canadian history podcast Preserves. $^{2}$

Preserves is our attempt to create a listenable scholarly podcast, as meticulously researched and cited as any academic literature and with a storytelling format that hopefully is enjoyable for a wide audience. As Moore describes us, we are "oral historians who have thought incessantly about transmission of knowledge through storytelling, fanatical podcast listeners, with the added bonus of one of us having a background in broadcasting/radio production."3 Our podcast website provides transcripts (footnoted after episode 3 !), sources, and credits. It is this experience as co-host, researcher, and writer for Preserves that led to my invitation to write this review essay.

1 See https://oralhistorycentre.ca. Thank you to Kent Davies and Kimberley Moore for their comments on earlier drafts of this piece. Thanks also to twitterstorians Mary Jane McCallum, Erin Millions, Tyler Yank, Krystl Raven, Dale Barbour, Katie McDonough, Keith Grant, Nancy Payne, and the Association for Manitoba Archives for their suggestions of Canadian history podcasts to review for this essay.

2 See https://99percentinvisible.org, https://www.cbc.ca/listen/cbc-podcasts/165-thefridge-light, and https://www.manitobafoodhistory.ca/preserves-pod.

3 Kimberly Moore, personal communication with author, e-mail, 1 June 2021. 
For those unfamiliar with how to access podcasts, the process is simple. If you have an iPhone or Apple computer, open the pre-installed Podcasts app, search for the title of the podcast (or a topic of interest), tap the show of your choice, and then tap "follow." For those with android phones, open the Google Play store, search for "Google Podcasts," and download and open the Google Podcasts app. Within Google podcasts, search for the title of the podcast (or topic) that interests you, tap the show of your choice, and then tap "subscribe." You can also follow podcasts by downloading and using other popular podcast apps such as Spotify, Stitcher, or Audible.

The proliferation of podcasts is a result of the low barrier of technological entry and the assumption that broadcasting skills or attention to aurality are not required. All that is needed, seemingly, is a computer, some free audio editing software, and a cheap microphone:

Podcasters can range from hobbyists who deliver a rambling monologue on their favourite topic heard by a few dozen people, to investigative journalists or narrative storytellers who create well researched and carefully crafted programmes, which are often available as both podcasts and broadcasts and can have many thousands of downloads a month, or more. ${ }^{4}$

A good podcast is one that reveals a breadth and depth of knowledge, not only of the subject matter but of the oral/aural medium itself. There is no shortage of podcasts that ignore their aurality, overlooking the value of "ambient sound [field recording, music, sound effects] to evoke mood and develop the narrative." Add in the pressure to produce weekly or biweekly episodes to maintain an audience and the result is a glut of "low-cost 'chumcasts'," with little educative or production value and by independent podcasters (most of them white males) without research and production teams. ${ }^{6}$

4 Siobhán McHugh, "How Podcasting is Changing the Audio Storytelling Cenre," Radio Journal: International Studies in Broadcast and Audio Media 14, no. 1 (January 2016): 66.

5 Siobhán McHugh, "The Affective Power of Sound: Oral History on Radio," Oral History Review 39, no. 2 (Summer/Fall 2012): 190.

6 McHugh, "How Podcasting is Changing the Audio Storytelling Genre," 78. Media scholar Sarah Murray states that the "sound" of podcasting is "perceived to be dominated by white 'bro-y' 'it boys' in talk and political podcasting"; see Sarah Murray, "Coming-of-Age in a Coming-of-Age: The Collective Individualism of Podcasting's Intimate Soundwork," Popular Communication: The International Journal of Media and Culture 17, no. 4 (May 2019): 303. 
The field of Canadian history is, not surprisingly, a very small part of the current podcast plethora. And yet podcasting, like radio, can be "especially well suited to telling the quieter, less well-known stories behind historical events - stories that complicate our understanding of what we think we know." For this review essay, I consider 14 podcasts that address Canadian history and are grouped into three categories: independent productions, official podcasts of organizations/associations, and podcasts by media production companies.

\section{Independents}

Historians, journalists, teachers, graduate students, ${ }^{8}$ and those in the heritage field have launched podcasts, drawing on their own expertise and connections but unaffiliated with their employers. These podcasts tend to be either monologues or interviews. Independent podcasts in Canadian history include Cool Canadian History, Canadian History Ehx, 1867 \& All That, Living Heritage, and Today in Canadian History. ${ }^{9}$

Cool Canadian History is hosted by David Borys, a Canadian military historian at UBC. Biweekly episodes of 20-30 minutes focus on Canadian military history, as well as the history of transportation, crime, Indigenous peoples, women, food, music, sports, politics, and race. Episodes are largely monologues, with the occasional episode dedicated to interviewing scholars about books they have recently authored. ${ }^{10}$ Like most podcasts discussed here, this one does not take advantage of the aural medium, with no field recording or music other than intros and outros. ${ }^{11}$ The podcast is nonetheless interesting

7 Stephen Smith, "Living History," in Reality Radio, ed. John Biewen and Alexa Dilworth, 2nd ed. (Durham, NC: University of North Carolina Press, 2017), 189.

8 See, for example, Minute Women (https://www.minutewomenpodcast.ca) by history graduate student Grace McNutt and Linnea Swimimer, which explores "the untold stories behind the iconic Canadian Heritage Minutes" as well as One Great History (https:// onegreathistory.wordpress.com) by University of Winnipeg and University of Manitoba masters history graduates Sabrina Janke and Alex Judge, which examines the history of Winnipeg.

9 See https://coolcanadianhistory.com, https://canadaehx.com, https://www.1867allthat.com, https://podcasts.apple.com/us/podcast/living-heritage-podcast/id1478642218 and http://todayincanadianhistory.org/podcast/.

10 See, for example, "The Fight for History with Dr. Tim Cook," Cool Canadian History podcast, season 6, episode 7, 29 November 2020, https://coolcanadianhistory. com/2020/11/29/s6e7-the-fight-for-history-with-dr-tim-cook/.

11 For more on field recording and aural history, see Kent Davies, Podcasting: Oral History Centre Workshop (Winnipeg: University of Winnipeg Oral History Centre, 2017); John F. Barber, "Digital Storytelling: New Opportunities for Humanities Scholarship and Pedagogy," Cogent Arts \& Humanities 3, no. 1 (May 2016): 1-14; and McHugh, "Affective Power of Sound," 187-206. 
to listen to, as the host makes good use of vocal modulation and pauses, and is a good storyteller. Unlike most Canadian history podcasts, which do not cite sources (even on their websites), Borys provides relevant book or podcast recommendations at the beginning of episodes.

Canadian History Ehx is hosted by former journalist Craig Baird. Semiweekly episodes of 20-30 minutes address war, the military, politics, sports, and Indigenous histories; there is also a series of episodes that focus on the history of small towns. ${ }^{12}$ Episodes are either monologues or (more interestingly) interviews with historians and notable Canadians (politicians, artists, authors, actors, musicians). Xylophone bumpers are the only nod to creativity in the aural medium..$^{13}$

1867 \& All That is hosted by Trent University historian Christopher Dummitt. Described as a "serialized continuous narrative" that covers the history of Canada from 1830 to 1885 , Dummitt, in the 30-40 minute episodes during the first season, explores the 1837-1838 rebellions and the development of "Responsible Government." Music is used to good effect throughout to enliven the monologue. The serialized format may not work well for those looking to use only individual episodes in their classrooms, as they can be difficult to follow outside their broader context.

Living Heritage (no website) is hosted by Dale Jarvis, a folklorist with the Heritage Foundation of Newfoundland and Labrador. Weekly episodes of 30 minutes examine the material culture, museums, archives, and craftspeople in Newfoundland and Labrador. Episodes consist of interviews with heritage preservationists with a connection to Newfoundland and Labrador, though topics may have interest for Canadianists in general. "Making Spruce Root Baskets," for example, includes archival audio and a public lecture about, as well as interviews with, Mi'kmaq artisans presented sequentially rather than integrated into a larger narrative. ${ }^{14}$

Today in Canadian History is hosted by public school teachers (and former radio directors) Marc Affeld and Joe Burima. Daily episodes of 5-10 minutes range across the history of war, arts, food, sports, labour, women, immigration,

12 See, for example, "The History of Altona," Canadian History Ehx, podcast episode 328, 26 April 2021, https://canadaehx.com/2021/04/26/the-history-of-altona/.

13 "Bumpers" are brief audio clips used as transitions between segments of a radio show or podcast. They are often musical excerpts. In this podcast, the bumpers are simply the sound of a xylophone.

14 "Making Spruce Root Baskets," Living Heritage, podcast episode 195, 19 November 2020, https://podcasts.apple.com/us/podcast/ep195-making-spruce-root-baskets/ id1478642218?i=1000499428918f. 
and other subjects. Music, interviews, and archival audio clips are effectively integrated throughout each episode. The hosts' backgrounds as educators and broadcasters are used to good effect, making it one of the highest quality, independently produced, Canadian history podcasts.

\section{Organizations/associations}

Several Canadian history associations and organizations produce their own podcasts to promote their scholarship and/or services. These include Canada's National History Society, the Champlain Society, Active History, NiCHE (Network in Canadian History \& Environment), and Know History.

Canada's History is the podcast of Canada's National History Society, hosted by a variety of employees. ${ }^{15}$ Episodes of 10-20 minutes, some in French, follow no consistent format and suffer from uneven audio and production quality. Some episodes are merely recordings of public lectures (e.g., "From Wall Street to Bay Street") offered without context, while others (e.g., "Cold War Tech and Its Discontents") effectively integrate narration, music, field recording, interviews, and archival audio. ${ }^{16}$ The latter are all too rare, as most episodes do not take advantage of the aural medium and include no field recording and no music other than intro and outro. This is particularly disappointing for episodes whose subject is music (e.g., "Folk on the Rocks"). Other episodes are nothing but field recording, devoid of discussion or even introduction ("Wee Robert's Song"). ${ }^{17}$

Witness to Yesterday | Témoins d'hier is the podcast of the Champlain Society, hosted by Greg Marchildon and Patrice Dutil, professors of public policy at University of Toronto and of politics and public administration at Ryerson respectively. ${ }^{18}$ Weekly episodes of 30-40 minutes feature interviews with scholars about their recent publications in all fields of Canadian history. Some episodes are in French; music is used as intro, outro, and occasional bumpers. Given

15 See https://www.canadashistory.ca/explore/podcasts\#/?page=1\&format=c26b0d46800d-483d-9 ${ }^{a}$ f2-15b7777527 b.

16 "From Wall Street to Bay Street," Canada's History podcast episode, 19 January 2021, https://www.canadashistory.ca/explore/business-industry/from-wall-street-to-bay-street; "Cold War Tech and Its Discontents," Canada's History, podcast episode, 27 January 2021, https://www.canadashistory.ca/explore/science-technology/cold-war-tech-and-itsdiscontents.

17 "Folk on the Rocks: An Enduring Festival," Canada's History podcast episode, 29 July 2020, https://www.canadashistory.ca/explore/arts-culture-society/folk-on-the-rocksan-enduring-festival; "Wee Robert's Song," Canada's History podcast episode, 16 January 2019, https://www.canadashistory.ca/explore/arts-culture-society/wee-robert-s-song. 
the podcast's format, it is odd that its website does not provide active links to publisher websites of the books discussed in each episode.

History Slam is the podcast of Active History and is hosted by Sean Graham, a historian at Parks Canada and Carleton University. ${ }^{19}$ Weekly episodes of 3060 minutes are conversational in style. Topics addressed are wide-ranging, and include the history of music, the military, women, policing, immigration, race, sports, politics, labour, childhood, religion, environment, arts, commemoration, and food. Episodes are primarily interviews with authors and filmmakers, and the podcast website includes links to the book discussed and its author, as well as a photo of the book cover. Episode webpages provide broader context for the episode, with active links to relevant content. Canadianists looking for a thoughtful and interesting introduction to history for their students should listen to the episode "Thinking Historically."

Nature's Past is the podcast of NiCHE, hosted by Sean Kheraj, a York University historian. ${ }^{21}$ Episodes are from 20 to 60 minutes long, and address such environmental history topics as natural resources, environmental activism, pollution, mining, and Indigenous histories as well as the field's historiography and methods. Episodes are primarily recorded interviews and panel discussions with academics and other experts. Unlike most podcasts reviewed in this essay, the podcast website usefully includes credits and sources, as well as links to books discussed.

Notice History is the podcast of Know History, a for-profit company that conducts historical research, and is hosted by its employees. ${ }^{22}$ Episodes of 30 minutes each consider the history of sports, museums, arts, leisure, and holidays via interviews with archivists, museum curators, and historians. Audio and production quality are uneven, with some episodes having imbalanced volume. Happily, the podcast website includes both credits and sources, with links to further reading.

\section{Media}

Not surprisingly - given the production team members that support them podcasts created by media companies tend to be well produced, effectively

19 See https://activehistory.ca/category/history-slam/.

20 "Thinking Historically," History Slam podcast episode 162, 24 September 2020, https:// activehistory.ca/2020/09/historyslam162/.

21 See https://niche-canada.org/naturespast/.

22 See https://www.knowhistory.ca/resources/notice-history-podcast. 
integrating various forms of audio to capture and maintain listeners' interest and to help explain their stories. Three of relevance to Canadian historians are Media Indigena, The Secret Life of Canada, and Unreserved. These not only pay close attention to aurality, but they also offer Indigenous and Indigenous feminist perspectives that are sadly missing from too many podcasts.

Media Indigena is hosted by Rick Harp and produced by INDIGENA Creative Group. ${ }^{23}$ Biweekly episodes are hour-long roundtable discussions of Indigenous issues and events by Indigenous people. Frequent participants are Candis Callison (University of British Columbia journalism professor), Brock Pitawanakwat (Indigenous Studies professor at University of Sudbury), Kim TallBear (Native Studies professor at University of Alberta), and Kenneth T. Williams (University of Alberta drama professor and playwright). Topics covered are diverse and often include a historical component (e.g., voting, advertising, academia, the Sixties Scoop, Idle No More, reparations, Indigenous languages, and even "rez dogs"). ${ }^{24}$ Episodes are highly listenable and both educational and entertaining. The website features transcripts for selected episodes only.

Unreserved is a CBC podcast hosted by author Falen Johnson (formerly hosted by author Rosanna Deerchild). ${ }^{25}$ Weekly 40-minute episodes discuss Indigenous history, culture, and current events. Episodes follow a storytelling format that integrates sequential interviews (with Indigenous scholars, authors, musicians, politicians, and community members) with music and field recordings. The podcast website provides detailed episode summaries, representative photos, and links to relevant news stories.

The Secret Life of Canada is another CBC podcast, hosted by author Falen Johnson and writer/performer Leah-Simone Bowen. ${ }^{26}$ Biweekly episodes of $40-$ 60 minutes (as well as 10-minute "Shout Out" mini-episodes) cover the history of Indigenous people, race, colonialism, environment, arts, women, gender, and sports. The double episodes "The Indian Pavilion at Expo 67" are typical, combining thorough historical research, evocative description, archived audio,

\footnotetext{
23 See https://mediaindigena.com/podcast/ and https://mediaindigena.libsyn.com.

24 For the latter, see "When Rez Dogs Become Settlers' Pet Projects," Media Indigena podcast episode 251, 31 March 2021, https://mediaindigena.libsyn.com/when-rez-dogsbecome-settlers-pet-projects-mi-251. See https://www.cbc.ca/listen/live-radio/1-105-unreserved. 
fascinating interviews, and appropriate sound effects. ${ }^{27}$ A team of seven is credited at the end of the episode: evidence that podcast quality improves with production and research assistance. The podcast website includes transcripts for all episodes as well as helpful teaching guides for selected episodes.

\section{Conclusions}

Podcasts can be a valuable tool for teaching and for disseminating research as more than three-quarters of Canadian adults have listened to them. ${ }^{28}$ Audiences who may not read peer-reviewed journals or attend academic conferences can be introduced to academic debates and insights through podcasts listened to on their daily commute or as they go about their chores at home. Podcasts are "among the most accessible formats for history learners outside the walls of the university - they are available for free, online and on demand." ${ }^{29}$

Podcasts are just beginning to make an impact on the field of Canadian history. The Canadian Historical Association's prizes still target books, articles, and teaching, but it is only a matter of time before there are prizes dedicated to digital outcomes like podcasts. Library and Archives Canada (Discover Library and Archives Canada), the Archives of Lesbian Oral Testimony (Lesbian Testimony Podcast), and Pier 21 (Countless Journeys) are among the many archives and museums across Canada that are developing their own podcasts to showcase their holdings. ${ }^{30}$ SSHRC, one of the most important funders of historical research in Canada, has been increasingly supportive of podcasts as a means of research dissemination. ${ }^{31}$ Over the past few years, SSHRC Connection

27 "The Indian Pavilion at Expo 67," Secret Life of Canada, podcast season 3, episodes 20 and 22, 15 February 2021 and 27 April 2021, https://www.cbc.ca/listen/cbc-podcasts/203the-secret-life-of-canada/episode/15825039-s3-the-indian-pavilion-at-expo-67-part-1 as well as https://www.cbc.ca/listen/cbc-podcasts/203-the-secret-life-of-canada/ episode/15840022-s3-the-indian-pavilion-at-expo-67-part-2.

28 Radio Connects, The Canadian Podcast Listener - A Landscape Study, summary report (October 2017), https://radioconnects.ca/wp-content/uploads/2016/09/The-CanadianPodcast-Listener-A-Landscape-Study.pdf.

29 Sadie Bergen, "History on the Download: Podcasting the Past," AHA Perspectives on History (29 February 2016), https://www.historians.org/publications-and-directories/ perspectives-on-history/march-2016/history-on-the-download-podcasting-the-past.

30 Discover Library and Archives Canada, https://www.bac-lac.gc.ca/eng/news/podcasts/ Pages/podcasts.aspx; Lesbian Testimony Podcast, https://alotarchives.org/blog; Countless Journeys, https://podcast.pier21.ca/episodes.

31 SSHRC partnered with Library and Archives Canada in 2017 to produce a podcast episode on the 150th anniversary of Confederation; see Library and Archives Canada, "Canada 150: Reflect and Reimagine" podcast episode, 30 November 2017, 
grants were awarded to develop podcasts on disabled workers, the rise of the radical right, public intellectualism, and women's writing. ${ }^{32}$ And in 2019, SSHRC funded the creation of the Amplify podcast network - "dedicated to reimagining the sound of scholarship" through production, peer-review, discoverability, and pedagogy of podcasts. ${ }^{33}$ Amplify is part of a growing effort by academic podcasters to have their work acknowledged as a form of scholarly production in and of itself, not merely as a way of publicizing scholarly work. ${ }^{34}$

History professors seeking to introduce their students to the digital humanities often turn to podcasts as an easy entry point - a phenomenon made more prevalent during the COVID-19 pandemic. Significantly increasing in 2020, university teaching centres, digital historians, and teachers promoted podcasts as a way to engage students while remote teaching, offering suggestions for both lessons and assessment. ${ }^{35}$ Podcasts also have become popular in graduate programs, and not only in the digital humanities. The history department at the University of Michigan, for example, launched

https://www.bac-lac.gc.ca/eng/news/podcasts/Pages/Canada-150-Reflect-Reimagine. aspx?utm_source=December+2017+\&utm_campaign=Dialogue_Dec_2017_EN .

32 SSHRC, "Award Recipients for Connections Grants: November 2020 Competition," https:// www.sshrc-crsh.gc.ca/results-resultats/recipients-recipiendaires/2020/cg-sc-nov2020eng.aspx; SSHRC, "Award Recipients for Connection Grants: 2018-19 Competitions," https://www.sshrc-crsh.gc.ca/results-resultats/recipients-recipiendaires/2019/ connection_connexion-eng.aspx; SSHRC, "Award Recipients for Connection Grants: February 2021 Competition," https://www.sshrc-crsh.gc.ca/results-resultats/recipientsrecipiendaires/2021/cg-sc-feb2021-eng.aspx.

33 SSHRC, "Award Recipients for Partnership Development Grants: November 2019 Competition," https://www.sshrc-crsh.gc.ca/results-resultats/recipientsrecipiendaires/2019/partnership_development_grants_2019-subventions_de_ developpement_partenerial_2019-eng.aspx; Amplify, https://amplifypodcastnetwork.ca.

34 Michael Rancic, "A Canadian Academic Podcast Network is Reimagining the Sound of Scholarship," University Affairs (4 February 2021), https://www.universityaffairs.ca/news/ news-article/a-canadian-academic-podcast-network-is-reimagining-the-sound-ofscholarship/.

35 Brianna Derr, "Remote Podcasting," Wake Forest University Center for the Advancement of Teaching (27 March 2020), https://cat.wfu.edu/2020/03/podcasting/; Aidan Kaplan, "Creative Assignments: Podcasting," University of Chicago Academic Technology Solutions (1 February 2019), https://academictech.uchicago.edu/2019/02/01/creative-assignmentspodcasting/; Chris Buddle, "Hear this! Podcasts as an Assessment Tool in Higher Education," Teaching for Learning @ McCill University (19 June 2013), https://teachingblog. mcgill.ca/2013/06/19/hear-this-podcasts-as-an-assessment-tool-in-higher-education/; Justin Hicks, Laura Winnick, and Michael Gonchar, "Project Audio: Teaching Students How to Produce Their Own Podcasts," New York Times (19 April 2018; updated 14 April 2020), https://www.nytimes.com/2018/04/19/learning/lesson-plans/project-audioteaching-students-how-to-produce-their-own-podcasts.html; Bret Zawiliski, "Your Final Assignment Is ... a Podcast," Bello Collective (8 July 2020), https://bellocollective.com/your-final-assignment-is-a-podcast-91b85e80585b. 
the podcast Reverb Effect in 2019 "as a training tool for graduate students" in "communication, digital skills, and collaborative and creative work." ${ }^{36}$

Podcasts generated by students as assignments can be ways to teach digital as well as more traditional skills; podcasts assigned by instructors as content can be ways to vary presentation styles and maintain student interest. History doctoral candidate Hayley Bowman explains this dual use of podcasts effectively in her articles for the American Historical Association's newsmagazine. Podcasts, she argues, "collapse space and time in a way that reading, writing, and even attending a lecture cannot .... Listening to and creating their own podcasts not only allow students to access information differently, they also encourage students to consider creative methods of communicating history." ${ }^{37}$ Podcasting teaches students skills common to essays (source selection and interpretation, contextual reading, analysis) but also new and equally important ones: "the succinct and appealing communication of an argument and story, interview methods, project management, and professional collaborations with others, from voice actors to production teams." The act of podcast creation requires of students "some creative thinking about the possibilities and limitations of the oral narrative medium. Because, in a podcast, the audience must listen, setting the scene with auditory cues and presenting source evidence in a way quickly intelligible for listeners becomes critical." ${ }^{38}$

Canadian historians looking to include podcasts in their syllabi's assigned "reading" would do well to incorporate episodes from the podcasts Today in Canadian History, Media Indigena, and The Secret Life of Canada discussed above. Those wanting to begin their own podcast are advised to participate in a podcasting workshop. University of Winnipeg's Oral History Centre offers such, and Wilfrid Laurier University launched a Podcaster-in-Residence program in

36 Daniele Sheinin, "Reverb Effect: A History Department Starts a Podcast," AHA Perspectives on History (5 November 2020), https://www.historians.org/publications-anddirectories/perspectives-on-history/november-2020/emreverb-effect/em-a-historydepartment-starts-a-podcast. For the podcast itself, see https://lsa.umich.edu/history/ history-at-work/reverbeffect.html.

37 Hayley R. Bowman, "A Climpse Behind the Curtain: Pedagogical Thinking with Podcasting and Narrative," AHA Perspectives on History (29 July 2021), https://www.historians.org/ publications-and-directories/perspectives-on-history/summer-2021/a-glimpse-behindthe-curtain-pedagogical-thinking-with-podcasting-and-narrative.

38 Hayley R. Bowman, "What Story Do You Want to Tell? Learning Narrative Storytelling through Podcasting," AHA Perspectives on History (8 July 2021), https://www.historians. org/publications-and-directories/perspectives-on-history/summer-2021/what-storydo-you-want-to-tell-learning-narrative-storytelling-through-podcasting (emphasis in original). 
2020.39 But there is no need for more "sonic brussels sprouts"40 in a landscape already cluttered with them. Just because one can create a podcast, does not mean one should.

In order to create something worth listening to, it is not sufficient to just have access to technology and/or expertise in subject matter. As digital media scholar John Barber reminds us, "The 'digital' part of the telling is not the story. The essential ingredients of a good narrative and effective storytelling - strong characters, compelling plot, conflict resolution - remain relevant. The focus then, of digital storytelling, is communicating compelling narratives in creative ways." ${ }^{41}$ Good podcasting, like good radio, requires editorial skill and proficiency with both field recording and aural history, necessitating an astonishing investment of time to produce a single episode. Ira Glass, host of This American Life, explains that this investment is why Radiolab is one of his favourite podcasts:

And so you end up with this super-polished production work where every note and phrase and breath is worked out to the microsecond. The timing and entrance of every little note, each of the sound effects, the quotes, the echo on the voices and music, the tinniness or bassy-ness of each element in the mix, it's all calibrated and machined like an expensive handmade watch. And all that meticulous work is in the service of something that's the opposite of careful and meticulous: this totally chatty, happy, loose, spontaneous-sounding conversation .... For my part, I find it comforting that this level of excellence is so labor intensive that they only can make ten full shows a year. ${ }^{42}$

Not every podcast must be a narrative, of course. But non-narrative podcasts, whether monologues, "chumcasts," or roundtables, would also benefit from greater attention to their aural construction. Scholarly podcasters (and their

39 "Podcasting 101," University of Winnipeg (29 March 2021), https://news.uwinnipeg.ca/ podcasting-101/; Wilfrid Laurier University, "Podcasting Studio," https://www.wlu.ca/ about/discover-laurier/strategic-initiatives/one-market/creativity-hub/podcastingstudio.html.

40 McHugh, "How Podcasting is Changing the Audio Storytelling Genre," 68, quoting Duke University audio program director John Biewen.

41 Barber, "Digital Storytelling," 11-12.

42 Ira Glass, "RadioLab: An Appreciation by Ira Glass," Transom (8 November 2011), http:// transom.org/2011/ira-glass-radiolab-appreciation/. 


\section{reviewers ${ }^{43}$ would do well to keep Glass's description in mind - and all the more so if they intend to involve their students in podcast production.}

\section{JANIS THIESSEN}

JANIS THIESSEN est professeure d'histoire à I'Université de Winnipeg. Elle est l'autrice de quatre livres qui portent sur les entreprises canadiennes, la main-d'œuvre et l'histoire orale, dont Snacks: A Canadian Food History (University of Manitoba Press, 2017). Son projet de recherche actuel se rapporte au Manitoba Food History Truck et au balado Preserves.

JANIS THIESSEN is a professor of history at the University of Winnipeg. She is the author of four books in Canadian business, labour, and oral history, including Snacks: A Canadian Food History (University of Manitoba Press, 2017). Her current research involves the Manitoba Food History Truck and the podcast Preserves.

43 See, for example, Wilfrid Laurier University Press's questions for peer evaluation of a scholarly podcast, which pay scant attention to aurality, in Siobhan McMenemy, "Scholarly Podcasting Open Peer Review," Wilfrid Laurier University Press, https://www.wlupress.wlu.ca/Scholarly-Podcasting-Open-Peer-Review. 